\title{
Health-related concerns of people who receive psychological support for inflammatory bowel disease
}

\author{
Robert G Maunder MD FRCPC, Elizabeth C de Rooy PhD, Brenda B Toner PhD CPsych, Gordon R Greenberg MD FRCPC, \\ A Hilary Steinhart MD FRCPC, Robin S McLeod MD FRCSC, Zane Cohen MD FRCSC
}

RG Maunder, EC de Rooy, BB Toner, et al. Health-related concerns of people who receive psychological support for inflammatory bowel disease. Can J Gastroenterol 1997;11(8):681-685.

BACKGROUND: People with inflammatory bowel disease (IBD) cope with a number of disease-specific concerns, which may result in referrals for supportive counselling.

OBJECTIVE: To determine differences between the healthrelated concerns of people with IBD who seek counselling or are referred for psychiatric assessment and those who have no recent contact with counselling or psychiatry.

METHODS: Forty-five consecutive patients with IBD referred for psychiatric consultation and 31 IBD out-patients who had recent counselling were compared with 190 IBD out-patients at the same hospital with no recent history of counselling. Diseaserelated concerns, demographic data and perceived symptom severity were assessed with self-report instruments.

RESULTS: Counselling patients had greater overall intensity of concern. Counselling patients differed from noncounselling patients on several measures related to illness severity and were more likely to be female. Correcting statistically for illness severity and sex, the counselled patients had significantly higher levels of concern about being a burden, pain and suffering, feeling out of control, financial difficulties, feeling alone, sexual performance, feeling dirty or smelly and being treated as different.

CONCLUSIONS: Beyond the intensity of their physical suffering, patients who seek counselling report a pattern of concern in which interpersonal and emotional concerns are prominent compared with those of out-patients who do not seek counselling. Clinicians should be aware of interpersonal concerns, which may increase the need for empathic support. Psychosocial interventions in IBD may be indicated without respect to psychiatric comorbidity.

Key Words: Counselling, Health-related quality of life, Inflammatory bowel disease, Psychological concerns
Les inquiétudes relatives à la santé des personnes qui reçoivent un soutien psychologique pour une maladie inflammatoire de l'intestin

RÉSUMÉ : Les personnes atteintes d'une maladie inflammatoire de l'intestin (MII) doivent faire face à un certain nombre d'inquiétudes spécifiques reliées à la maladie pouvant aboutir à des consultations pour obtenir un soutien psychologique. On a identifié les différences entre les inquiétudes relatives à la santé chez les sujets atteints d'une MII qui recherchent un counseling ou qui sont adressées à un psychiatre pour être évaluées et les inquiétudes des personnes n'ayant subi aucun counseling récent ou n'ayant pas récemment consulté un psychiatre.

MÉTHODES : Quarante-cinq patients atteints de MII qui ont été adressés à un psychiatre et 31 patients ambulatoires atteints d'une MII qui ont récemment subi un counseling ont été comparés à 190 patients ambulatoires atteints d'une MII et sans histoire récente de counseling. Ces patients provenaient du même hôpital. Les inquiétudes relatives à la santé, les données démographiques et la perception de la gravité des symptômes ont été évalués avec des instruments d'auto-évaluation.

RÉSULTATS : Les patients qui ont subi un counseling étaient globalement plus inquiets. Ils différaient des autres patients dans plusieurs mesures ayant rapport avec la gravité de la maladie et étaient plus souvent des femmes. Une correction statistique pour la gravité de la maladie et le sexe démontrait que les patients ayant subi un counseling se souciaient beaucoup plus d'être un fardeau, de la souffrance psychologique et de la douleur, d'avoir l'impression de perdre la maîtrise, des difficultés financières, de l'isolement, de leur performance sexuelle, de se sentir sales ou de sentir mauvais, et d'être traités comme des personnes différentes.

CONCLUSIONS : Au delà de l'intensité de leur souffrance physique, les patients qui recherchent un counseling présentent un schéma d'inquiétudes où les inquiétudes interpersonnelles et émotionnelles prédominent comparativement à celles des patients ambulatoires qui ne consultent pas. Les cliniciens ne doivent pas négliger les inquiétudes interpersonnelles qui peuvent accroître le besoin d'empathie. Les interventions psychosociales dans la maladie inflammatoire de l'intestin peuvent être indiquées en dehors de toute considération d'une comorbidité psychiatrique.

Departments of Psychiatry, Gastroenterology and Surgery, Mount Sinai Hospital; Departments of Internal Medicine and Surgery, University of Toronto; Women's Mental Health Research Programme, Clarke Institute of Psychiatry, Toronto, Ontario; Wayne State University, Detroit, Michigan Correspondence and reprints: Dr RG Maunder, Department of Psychiatry, 9th Floor, Mount Sinai Hospital, 600 University Avenue, Toronto, Ontario M5G 1X5. Telephone 416-586-3200, fax 416-586-8654, e-mail bmaunder@interlog.com

Received for publication April 22, 1997. Accepted July 4, 1997 
$\mathrm{I}_{\mathrm{i} i \mathrm{i}}^{\mathrm{n}}$ flammatory bowel disease (IBD) comprises ulcerative colitis and Crohn's disease - two chronic inflammatory diseases of the gastrointestinal tract that cause pain, diarrhea, bleeding and other symptoms. The recent development of valid and reliable instruments to measure health-related quality of life in IBD has resulted in an emerging profile of the prominent illness-related concerns of people with these diseases (1) and the recognition that subjective quality of life is an important outcome measure in treating IBD (2). A large body of literature, which attempts to link psychological factors to the course of ulcerative colitis (3) and Crohn's disease (4), suggests that IBD is probably not different from other chronic illnesses with respect to psychiatric comorbidity, but little information is available about the problems that people with IBD cope with, irrespective of the presence or absence of psychiatric diagnosis.

It is a common clinical observation that a small group of patients with IBD are especially distressed by their illness. These people may benefit from extra support or help with coping. In the IBD Centre at Mount Sinai Hospital, a psychosocial support team is available to assess these needs and intervene. Patients may be referred by their doctor or nurse, or they may refer themselves to a psychiatrist for IBD-related concerns. Illness-specific interventions, such as professionally led IBD supportive therapy groups, are being developed. In this context, it is important to determine whether the IBD-related concerns of people who come for counselling are different from the concerns of IBD patients in general. Furthermore, we wished to explore whether differences are related to the severity of IBD symptoms or to other variables.

Tailoring psychosocial intervention to the specific needs of IBD patients appears to be important because the current literature regarding psychosocial interventions in IBD shows mixed results from the application of techniques derived in other illness groups (5), including one trial in which a group treated with a combination of cognitive and behavioural techniques showed worsening of symptoms compared with a control group (6).

We report the health-related concerns of IBD patients who come for counselling and how they differ from the concerns of IBD patients in an out-patient gastroenterology clinic who have had no recent counselling contact.

\section{PATIENTS AND METHODS}

Subject recruitment: Two hundred and fifty-three subjects with IBD identified in an out-patient gastroenterology clinic at a tertiary care centre consented to complete the Rating Form of IBD Patient Concerns (RFIPC) (7), a self-report instrument that probes the degree of concern felt about each of 25 items related to IBD. Subjects also provided demographic information and IBD-related medical history, including a self-rating of the severity of 13 symptoms related to IBD. This study was approved by the University of Toronto Human Subjects Review Committee.

A post-hoc comparison group was formed by chart review of 50 consecutive IBD patients who were referred for psychiatric assessment at the same centre within two years of the out-patient study. Forty-five of these patients had completed the RFIPC in the process of clinical assessment. Demographic, medical history and symptom severity data drawn from the same self-report form used in the out-patient survey were also recorded. Patients referred to psychiatry differed from the original study sample in that they included both gastroenterological in-patients and out-patients. Overlap between the original out-patient sample and the psychiatric sample could not be determined accurately but was considered to be small based on the information gathered at the time of psychiatric consultation.

Formation of comparison groups: All subjects were asked whether they had had psychotherapy or counselling in the past six months. Two hundred and twenty-one of the gastrointestinal clinic patients and 43 of the psychiatric referral patients answered this question, providing four clinical groups: gastrointestinal clinic patients without recent counselling $(n=190)$; gastrointestinal clinic patients with recent counselling $(n=31)$; psychiatric referral patients without recent counselling $(n=19)$; and psychiatric referral patients with recent counselling $(n=24)$. The latter three groups were compared to test for equivalency on the mean RFIPC and item scores using an uncorrected one-way ANOVA. The results supported combining all subjects who answered the counselling question into two groups - those with a recent history of counselling or a current psychiatric referral ('counselling patients') and gastrointestinal clinic patients without recent counselling ('noncounselling patients'). The two patients referred to psychiatry who did not indicate whether they had recent counselling but completed the RFIPC were subsequently included as counselling patients.

Comparison of counselling with noncounselling groups: Demographic data and data related to diagnosis and IBD symptom severity were compared for counselling and noncounselling patients by using $t$ tests for continuous variables and $\chi^{2}$ for dichotomous variables. In the absence of data required for valid measurement of disease activity, perceived symptom severity was measured by self-report of 13 symptoms related to IBD (abdominal pain, diarrhea, bleeding, fever, nausea/vomiting, joint pain/swelling, skin disease, eye disease, loss of bowel control, difficulty with gas, frequent trips to the bathroom, dependence on medication for diarrhea and dependence on medication for pain). Each item was graded on a four-point scale, and the sum was calculated. This scale was not validated against objective measures of disease activity. Other measures related to illness severity were similarly compared among groups.

Given the post-hoc assembly of comparison groups and a lack of a priori hypotheses about group differences, data analysis was designed conservatively. To determine whether counselling status contributed independently to concerns, repeated measures multivariate analysis of 25 RFIPC items between counselling and noncounselling groups was performed, covarying for sex, summed symptom severity and all other recorded measures of illness severity that differed among groups (see Table 1). After this was found to be significant, univariate analysis using the Bonferroni correction 
TABLE 1

Comparison of demographic and illness-related variables in counselling and noncounselling patients

\begin{tabular}{lccc}
\hline & $\begin{array}{c}\text { Noncounselling } \\
(\mathbf{n = 1 9 0 )}\end{array}$ & $\begin{array}{c}\text { Counselling } \\
(\mathbf{n = 7 6 )}\end{array}$ & $\mathbf{P}^{*}$ \\
\hline Age (years) & 34.6 & 35.2 & $\mathrm{~ns}$ \\
Education (years) & 14.35 & 14.32 & $\mathrm{~ns}$ \\
Sex (\% female) & 53 & 68 & $\mathrm{~ns}$ \\
Diagnosis (\% ulcerative colitis) & 45 & 50 & $\mathrm{~ns}$ \\
Stress-related (1 = never, 3 = always) & 2.3 & 2.4 & $<0.001$ \\
Well-being today (1 = well, 5 = terrible) & 1.74 & 2.32 & 0.04 \\
Weight (kg) & 68.64 & 64.56 & 0.002 \\
Percentage of time without symptoms & 44.1 & 30.6 & 0.04 \\
Medical doctor visits in past six months & 3.86 & 6.61 & 0.008 \\
Hospital admissions in past two years & 1.16 & 1.97 & 0.003 \\
Summed symptom severity (0 to 42) & 9.53 & 12.67 & \\
\hline
\end{tabular}

${ }^{*} \chi^{2}$ for discrete variable and $\mathrm{t}$ tests for continuous variables. ns Nonsignificant

TABLE 2

Concerns that differ between counselling and noncounselling patients, controlling for perceived illness severity and sex

\begin{tabular}{lccc}
\hline & $\begin{array}{c}\text { Counselling }(\mathbf{n = 7 6 )} \\
\text { item mean }\end{array}$ & $\begin{array}{c}\text { Noncounselling }(\mathbf{n = 1 9 0 )} \\
\text { item mean }\end{array}$ & $\mathbf{F}^{*}$ \\
\hline Being a burden & 63.26 & 41.24 & 0.014 \\
Pain or suffering & 59.96 & 40.27 & 0.027 \\
Feeling out of control & 59.63 & 37.10 & 0.014 \\
Financial difficulties & 54.50 & 33.07 & 0.017 \\
Being alone & 53.29 & 21.54 & $<0.001$ \\
Sexual performance & 48.39 & 27.07 & 0.031 \\
Feeling dirty or smelly & 39.95 & 25.07 & 0.007 \\
Being treated as different & 36.58 & 20.78 & 0.048 \\
\hline
\end{tabular}

* Univariate F tests using the Bonferroni correction for multiple comparisons, covarying for self-reported symptom severity, other indexes of illness severity (see Table 1) and sex

for multiple comparisons was employed to determine significant between-group differences on individual RFIPC items again covarying for sex and illness severity variables.

To survey the leading concerns among counselling patients, without respect to their differences from the noncounselling group, mean RFIPC item scores in counselling patients were ranked. Statistical analyses were performed with the Statistical Package for Social Sciences software (SSPS Inc, Chicago).

\section{RESULTS}

In comparisons among the three categories of patients who had been referred for or had attended counselling (gastrointestinal clinic patients with recent counselling, psychiatric referral patients without recent counselling or psychiatric referral patients with recent counselling), no significant differences were found on any of the 25 RFIPC items or the overall mean RFIPC score. Nor were significant differences found in age, sex, diagnosis or perceived symp- tom severity. Therefore, these three groups were collapsed into one ('counselling patients') for subsequent analysis.

Table 1 illustrates that the samples of counselling patients and noncounselling patients did not differ by age, IBD diagnosis or education. Women were represented more highly among the counselling patients. Data related to illness severity consistently suggest greater severity in the counselling patients, as one might expect based on the presence of in-patients in this group. Thus, the sample of counselling patients reported significantly greater symptom severity, recent doctor visits and hospital admissions, and less time without symptoms, worse general well-being and lower weight.

The mean score on the RFIPC was significantly elevated in the counselling group $(52.50 \pm 20.14$, mean \pm SD) compared with the noncounselling group (37.63 \pm 21.45 , $\mathrm{P}<0.001)$. There was no significant difference in mean RFIPC or counselling status between ulcerative colitis and Crohn's disease patients.

In analysis of differences between groups on the items of 
the RFIPC, it was necessary to control statistically for two confounding factors: illness severity and sex. Mean RFIPC score was found to be correlated with symptom severity (correlation coefficient $0.44, \mathrm{P}<0.001$ ). In addition, mean RFIPC was significantly different between men $(36.9915 \pm 22.142)$ and women $(45.7480 \pm 21.704, \mathrm{P}=0.001)$. MANOVA, covarying for these confounding factors, found a significant independent contribution of counselling status to RFIPC results $(\mathrm{F}=0.039)$. Univariate ANOVA using the Bonferroni correction for multiple comparisons, again covarying for sex and illness severity variables, demonstrated a statistically significant difference between counselling and noncounselling patients for eight of the 25 RFIPC items (Table 2).

The RFIPC items that were significantly higher in counselling patients than in noncounselling patients include interpersonal concerns (being a burden, being alone or being treated as different), self-image and self-control items (sexual performance, feeling dirty or smelly, or feeling out of control) and other stressors (pain or financial concerns). It is noteworthy that two additional items that were significant in the ANOVA when covarying only for illness severity attractiveness and feelings about your body - fell to insignificance after covarying for sex.

Ranked means of RFIPC items scores in the counselling group revealed that some items that do not differ significantly among groups remain prominent among patients who seek counselling. The top ten concerns in counselling patients in rank order are energy level, reaching one's full potential, the uncertain nature of the illness, being a burden, medication effects, loss of bowel control, pain and suffering, feeling out of control, having surgery and feelings about one's body.

\section{DISCUSSION}

The comparison of IBD-related concerns between patients who have had recent contact with psychiatry or counselling and those who have not suggests that these groups have different patterns of concern. The least surprising finding is a high intensity of concern among those who seek psychosocial help or are referred for assessment. More subtly, we find that among those who seek counselling, relatively more attention is given to interpersonal concerns, concerns about self-control or self-image, pain and financial difficulties. These concerns predict counselling status after controlling for perceived illness severity and sex. Naturally, perceived symptom severity is strongly associated with overall degree of concern, and this in itself may lead some people to counselling. Nonetheless, we find a group of personal or emotional concerns that lead people to counselling, independent of the effects of symptom severity. Physicians seeing people with IBD should be vigilant for difficulties in these interpersonal areas because they may be markers for individuals in need of extra support and in some cases a referral for psychosocial assessment or intervention.

Gender issues are often relevant to counselling and to the experience of illness. These data support paying extra atten- tion to concerns over attractiveness and body image in women with IBD.

In designing appropriate psychosocial interventions for people who perceive themselves as having difficulty with IBD and therefore seek counselling, it is important to understand not just what separates these people from those who do not seek counselling, but also what their most prominent concerns are in general. The rank order of mean RFIPC item scores in the counselling suggests that several items that do not contribute directly to counselling status are nonetheless of great concern, such as energy level, reaching full potential, the uncertain nature of the illness, medication effects, loss of bowel control, having surgery and feelings about one's body.

Data are not available on the source of referral of the counselling patients in this sample. From clinical experience at this centre, we estimate that in about half of the patients seeking a psychiatric consultation, the request comes first from the patient. That patients with this profile of concerns seek out mental health professionals may suggest the need for appropriately designed IBD-specific psychosocial interventions, or may reflect the perception or expectation that empathic support from primary caregivers is unavailable or insufficient.

There are important limitations on the interpretation of these data due to our methodology. The most significant caveat is that the reported comparison data from psychiatric referrals were gathered for post-hoc analysis by chart review, unlike the gastrointestinal out-patient data, which were gathered as part of a study design. The population of patients referred for psychiatric care differs with respect to important confounding variables related to illness severity. The psychiatric data, nonetheless, were gathered from consecutive referrals to psychiatric care in the same centre within the two-year period of the study data, and so are likely to be comparable in most respects and unaffected by most selection biases (except the desired selection for psychiatric concern). While we controlled for the difference in perceived symptom severity and other severity indexes statistically, more confidence could be justified by a planned comparison of counselling and noncounselling patients matched for illness severity, with illness severity measured by an objective standard.

Another criticism of this study is that the interpersonal concerns endorsed on the RFIPC questionnaire by counselling patients may not in fact be related to illness, ie, people with significant interpersonal troubles that may have led them to counselling anyway, also, by coincidence, have IBD. Intuitively, it is likely that pre-existing personality and coping-style factors have a substantial impact on the ability to adapt to chronic illness, as they do in other areas of life. Our clinical experience is that IBD patients referred to psychiatric care at a tertiary care IBD centre almost invariably focus their concern on disease-related issues. From the data, the high correlation of mean RFIPC and symptom severity suggests that there is a strong relationship between the experience of illness and seeking counselling in these patients. 
Data relating to several common reasons for referral to psychiatric care are not presented here, including psychiatric diagnosis, concern about suicide risk, and behavioural or personality difficulties between the patient and the treatment team. In a separate study of 43 patients referred to psychiatric care at our centre (8) (many patients overlapped with the current sample), we reported that comorbid psychiatric diagnosis is present in $47 \%$, with the preponderance of diagnoses being depression or anxiety disorder. Adjustment disorder and other problems of coping or adaptation in the absence of a significant psychiatric diagnosis was present in $53 \%$. We advocate that general practitioners, gastroenter-

\section{REFERENCES}

1. Drossman DA, Leserman J, Mitchell M, Li Z, Zagami EA, Patrick DL. Health status and health care use in persons with inflammatory bowel disease: A national sample. Dig Dis Sci 1991;36:1746-55.

2. Maunder RG, Cohen Z, McLeod RS, Greenberg G. Effect of intervention in inflammatory bowel disease on health-related quality of life: a critical review. Dis Colon Rectum 1995;38:1147-61.

3. North CS, Clouse RE, Spitznagel EL, Alpers DH. The relation of ulcerative colitis to psychiatric factors: a review of findings and methods. Am J Psychiatry 1990;147:974-81.

4. North CS, Alpers DH. A review of studies of psychiatric factors in Crohn's disease: etiologic implications. Ann Clin Psychiatry 1994;6:117-24 ologists and mental health professionals all attend to the broad spectrum of disease-related concerns in IBD patients and not just to psychiatric diagnoses when considering the need for interpersonal support or psychiatric consultation.

It is noteworthy that no difference was found between patients with a recent history of counselling and those with new psychiatric referrals and no such history. Psychosocial intervention may increase distress in treated subjects relative to controls (6), and so it is important to note that the increased concern in patients with a recent history of counselling appears to precede counselling and is therefore unlikely to be iatrogenic.

5. Schwarz SP, Blanchard EB. Inflammatory bowel disease: a review of the psychological assessment and treatment literature. Ann Behav Med 1990;12:95-105.

6. Schwarz SP, Blanchard EB. Evaluation of a psychological treatment for inflammatory bowel disease. Behav Res Ther 1991;29:167-77.

7. Drossman DA, Leserman J, Li Z, Mitchell CM, Zagami EA, Patrick DL. The rating form of IBD patient concerns: a new measure of health status. Psychosom Med 1991;53:701-12.

8. Maunder RG, Cardish RJ. Psychological factors affecting medical condition: prevalence and difficulty applying the diagnosis in inflammatory bowel disease. Psychosom Med 1996;58:91. 


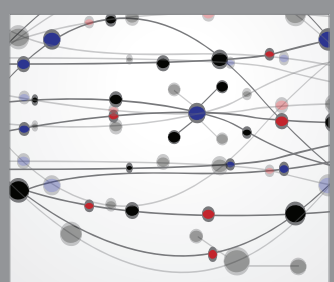

The Scientific World Journal
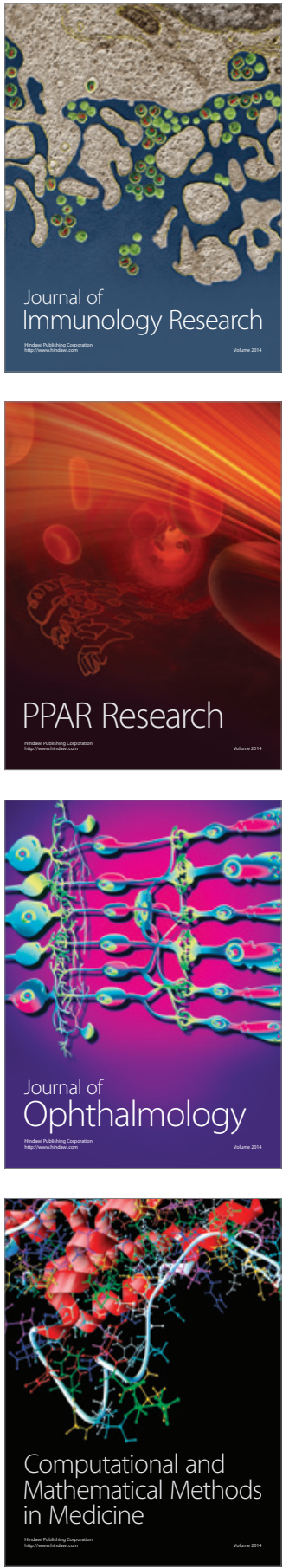

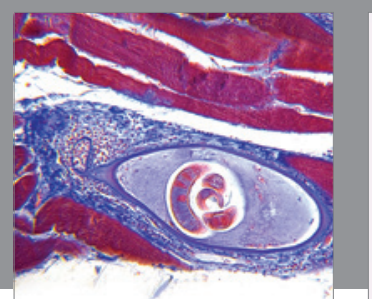

Gastroenterology Research and Practice

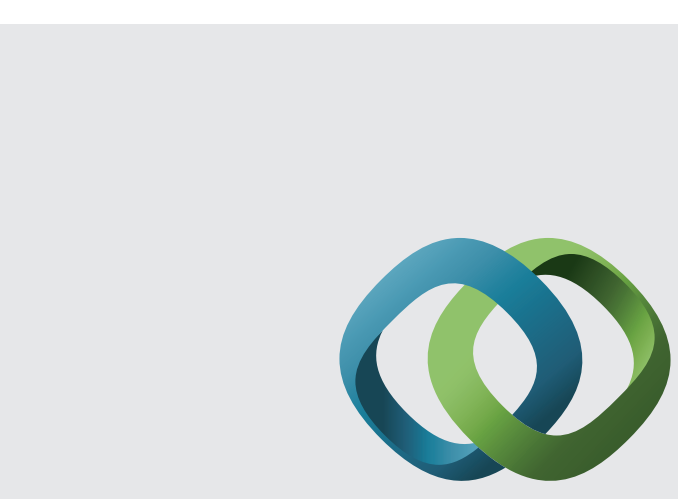

\section{Hindawi}

Submit your manuscripts at

http://www.hindawi.com
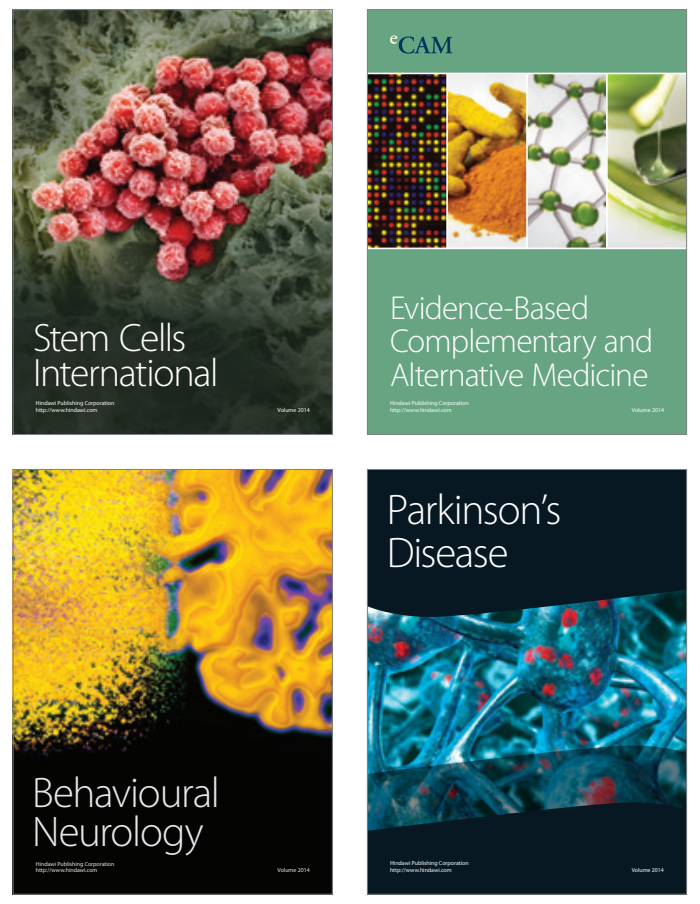
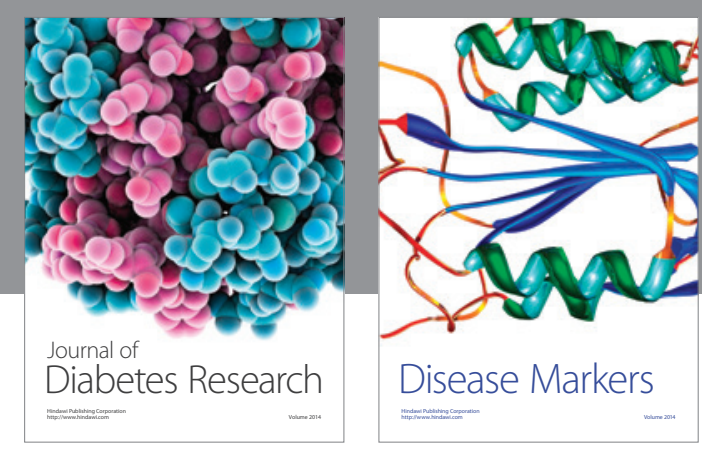

Disease Markers
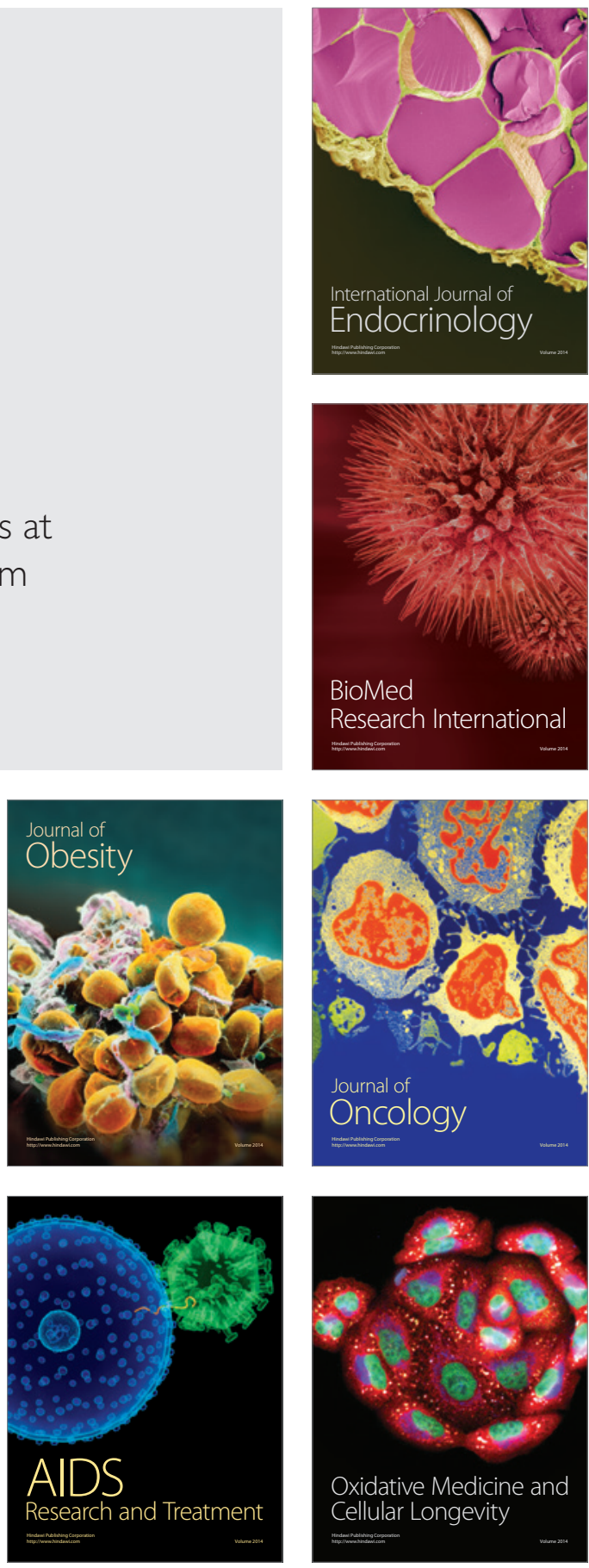